\title{
A Review on Recent Developments in Desalanisation by Forward Osmosis (FO) and Reverse Osmosis (RO)
}

\author{
Gitanjali Sharma and Harpreet Kaur \\ Department of Chemistry, Baddi University, Baddi
}

\begin{abstract}
Osmosis is a physical phenomenon in which solvent molecules move through a semipermeable membrane from a dilute solution towards more concentrated solution. Initially, the mechanism of osmosis through natural materials was studied but now a days scientists have given special attention to osmosis via synthetic materials. Osmosis, or as it is currently referred to as Forward Osmosis (FO), has new applications in separation processes for wastewater treatment and seawater/brackish water desalination. Reverse Osmosis (RO), a process by which a solvent passes through a porous membrane in the direction opposite to that for natural osmosis when subjected to a hydrostatic pressure greater than the osmotic pressure. is currently the most important desalination technology and it is experiencing significant growth.
\end{abstract}

\section{Introduction}

Providing clean and affordable water to meet human needs is a grand challenge of the 21 st century. Worldwide, water supply struggles to keep up with the fast growing demand, which is exacerbated by population growth, global climate change, and water quality deterioration ${ }^{1,2,3,4}$. In recent decades, increased domestic, agricultural and industrial activities worldwide have led to the release of various pollutants, such as toxic heavy metals, inorganic anions, organics, micropollutants and nutrients into the aquatic environment. The removal of these wide varieties of pollutants for better quality of water for various activities is an emerging issue and a robust and eco-friendly treatment technology is needed for the purpose. It is well known that cellulosic materials can be obtained from various natural sources and can be employed as cheap adsorbents ${ }^{5}$. In recent years, semiconductor photocatalytic process has also shown a great potential as a low-cost, environmental friendly and sustainable treatment technology to align with the "zero" waste scheme in the water/wastewater industry. The ability of this advanced oxidation technology has been widely demonstrated to remove persistent organic compounds and microorganisms in water. At present, the main technical barriers that impede its commercialisation remained on the post-recovery of the catalyst particles after water treatment ${ }^{6}$.

Osmosis through asymmetric membranes has been studied as a means of desalination via forward osmosis and power generation through a process known as pressure retarded osmosis. The primary obstacle to using asymmetric membranes for osmotic processes is the presence of internal concentration polarization, which significantly reduces the available osmotic driving force ${ }^{7}$. The emergence of nano-technology in membrane materials science could offer an attractive alternative to polymeric materials ${ }^{8}$. Cellulose acetate (CA) nanofiltration (NF) hollow fiber membranes have been fabricated and tested in the forward osmosis (FO) process. A two-step heat-treatment, i.e., $60 \mathrm{~min}$ at $60{ }^{\circ} \mathrm{C}$ and $20 \mathrm{~min}$ at $95{ }^{\circ} \mathrm{C}$, effectively shrinks the membrane mean pore radius from 0.63 to $0.30 \mathrm{~nm}$. The molecular weight cut off (MWCO) of the resultant CANF membrane is $186 \mathrm{Da}$. In the NF experiments under 1 bar transmembrane pressure, the newly developed CA NF membrane shows a pure water permeability (PWP) of $0.47 \mathrm{Lm}^{-2} \mathrm{bar}^{-1} \mathrm{~h}^{-1}$ and rejection levels of $90.17 \%$ to $\mathrm{NaCl}$ and $96.67 \%$ to $\mathrm{MgCl}_{2}{ }^{9}$. The design and engineering of membrane structure that produces low salt leakage and minimized internal concentration polarization (ICP) in forward osmosis (FO) processes have been explored in this work. The fundamentals of phase inversion of cellulose acetate (CA) regarding the formation of an ultrathin selective layer at the bottom interface of polymer and casting substrate were investigated by using substrates with different hydrophilicity. An in-depth understanding of membrane structure and pore size distribution has been elucidated with field emission scanning electronic microscopy (FESEM) and positron annihilation spectroscopy (PAS). A double dense-layer structure is formed when glass plate is used as the casting substrate and water as the coagulant. The thickness of the ultra-thin bottom layer resulted from hydrophilic-hydrophilic interaction is identified to be around $95 \mathrm{~nm}$, while a fully porous, open-cell structure is formed in the middle support layer due to spinodal decomposition. Consequently, the membrane shows low salt leakage with mitigated ICP in the FO process for seawater desalination ${ }^{10}$. With the aid of positron annihilation lifetime spectroscopy (PALS), the similarity in physicochemical properties between the polymer and the substrate was found to play a significant role in determining the porosity of the bottom interfacial layer. The structure of the dense interfacial layer was also strongly dependent on membrane thickness and solvent composition. Experimental results surprisingly reveal that the original pore size of the as-cast membrane plays a 
critical role determining the final performance of the subsequent annealed membrane independently of annealing temperature and time ${ }^{11}$.

With the rapidly increasing demands on water resources, fresh water shortage has become an important issue affecting the economic and social development in many countries. As one of the main technologies for producing fresh water from saline water and other wastewater sources, reverse osmosis (RO) has been widely used so far. Reverse osmosis membrane technology has developed over the past 40 years to a $44 \%$ share in world desalting production capacity, and an $80 \%$ share in the total number of desalination plants installed worldwide. The use of membrane desalination has increased as materials have improved and costs have decreased. Today, reverse osmosis membranes are the leading technology for new desalination installations, and they are applied to a variety of salt water resources using tailored pretreatment and membrane system design. Two distinct branches of reverse osmosis desalination have emerged: seawater reverse osmosis and brackish water reverse osmosis ${ }^{12}$. A seawater desalination process separates saline seawater into two streams: a fresh water stream containing a low concentration of dissolved salts and a concentrated brine stream. The process requires some form of energy to desalinate, and utilizes several different technologies for separation. Two of the most commercially important technologies are based on the multi-stage flash (MSF) distillation and reverse osmosis (RO) processes ${ }^{13}$. However, a major challenge facing widespread application of RO technology is membrane fouling, which results in reduced production capacity and increased operation costs. Till date polymeric membranes have dominated the RO desalination industry. From the late 1950s to the 1980s the research effort focussed on the search for optimum polymeric membrane materials. With the aid of positron annihilation lifetime spectroscopy (PALS), the similarity in physicochemical properties between the polymer and the substrate was found to play a significant role in determining the porosity of the bottom interfacial layer ${ }^{14}$.In subsequent decades the performance of RO membranes has been optimised via control of membrane formation reactions, and the use of poly-condensation catalysts and additives. Nevertheless, the advances in membrane permselectivity in the past decade has been relatively slow, and membrane fouling remains a severe problem. Reverse osmosis membranes processing natural and waste waters are often exposed to low concentrations of chlorine in feed water. This biocide is chemically aggressive toward most commercial high performance membrane polymers. Chemical attack by chlorine ultimately results in membrane failure as measured by enhanced passage of both salt and water ${ }^{15}$.

In comparison to the ordinary forward osmosis process, the ultrasound-assisted forward osmosis process resulted in higher water fluxes in case of sweet lime juice as well as rose extract containing anthocyanin. The degradation of rose anthocyanin due to ultrasound was found to be $1.82 \%{ }^{16}$. Forward osmosis (FO) has attracted attention in industry because of its low energy consumption and low fouling tendency ${ }^{17}$. Pressure assisted forward osmosis (PAFO) was used instead of FO to increase the water production rate. It had been found that water production in PAFO was increased by $9 \%$ and $29 \%$ at applied pressure of 2 and 4 bars ${ }^{18}$. A new Forward osmosis-Electrodialysis-Reverse osmosis (FO-ED-RO) hybrid system employs FO element upstream to ED-RO system for an access to draw solutions with higher electrical conductivity, aiming at reducing energy consumption and inheriting various advantages of ED system ${ }^{19}$. Forward osmosis (FO) nowadays considered a breakthrough technology that can be potentially used for concentrating suspensions and solutions, including wastes such as sewage. The sewage concentration by FO represented a habilitating technology enabling the application of a wider range of treatment alternatives ${ }^{20}$. The membrane flux increased by $93.3 \%$ due to temperature increase from 20 to $26{ }^{\circ} \mathrm{C}$ and the flow rate from 1.2 to $3.2 \mathrm{~L} / \mathrm{min}$ using a $0.5 \mathrm{M}$ $\mathrm{NaCl}$ solution as the draw solution and distilled water as the feed solution (FS) ${ }^{21}$. High permselectivity of osmosis based on nanocomposite of mesoporous silica nanoparticles and nanofibers by electrospinning were analysed $^{22}$.

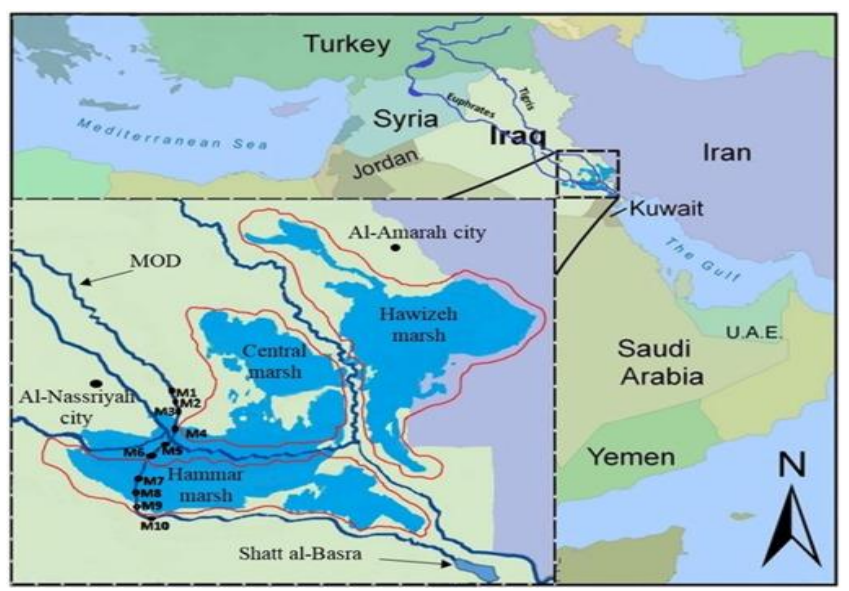

Fig.1 The Third River in Iraq 
Osmosis played an important role in providing good water quality at Iraq. Around $150,000 \mathrm{~km}^{2}$ of Iraqi agricultural lands drain into by the Main Outfall Drain, formerly called The Third River, shown in Fi.1. The MOD is situated between the Tigris and Euphrates Rivers, and passes through the main Mesopotamian marshlands south of these rivers. According to the Iraqi Ministry of Agriculture, the river has suffered from very high salt concentrations since it was constructed in 2008. It has a length of $565 \mathrm{~km}$ from north of Baghdad to the Arabian Gulf with the total discharge of $210 \mathrm{~m}^{3} / \mathrm{s}$. Drainage water is released into Shat AL Basra canal and then flows into the Arabian Gulf. The salt rejection can be reduced from $97 \%$ to $88 \%$ to obtain high quantities of fresh water with an agriculturally acceptable (lower quality) by osmosis ${ }^{23}$.

Salt rejection coefficient is an appropriate measure for the selectivity of a membrane when chosen for osmosis. The amount of RO concentrate waste water requiring disposal must be as minimal as possible (near zero-discharge); the recovery of high quality water should be as high as possible ${ }^{24,25}$. Membrane solids is a complex phenomenon involving the deposition of several types of solids on the membrane surface. If it occurs, the permeability of the RO membrane lowered, which in turn affects the energy requirement ${ }^{26}$. RO has been used widely for various water and wastewater treatment processes, in areas with scarce water supplies (as a means of sea-water desalination) and importantly for this study the treatment of brackish water ${ }^{27,28}$.

The benefits of reverse osmosis are its small footprint, a modular design and the possibility of automatic process control and relatively low cost of water production ${ }^{29}$.

Other unique benefits of forward osmosis include pressure-retarded osmosis for generation of electricity from saline and fresh water and implantable osmotic pumps for controlled drug release beside utilisation in separation of pure water in water treatment ${ }^{30}$.

\section{Conclusion}

Forward osmosis (FO) has attracted growing attention in many potential applications such as power generation, desalination, wastewater treatment and food processing. However, there are still several critical challenges, including concentration polarization, membrane fouling, reverse solute diffusion and the need for new membrane development and draw solute design in FO.

The field of RO membrane desalination has rapidly grown and Membrane technology has improved, allowing significant increases in product production and cost savings. RO recovery is primarily limited by osmotic pressure increase and organic material fouling. However further improvements in membrane technology will allow a wider application of RO to inland and rural communities.

\section{References}

[1]. XiaoleiQu,PedroJ.J.Alvarez, Qilin Li., “Applications of nanotechnology in water and wastewater treatment”, Water Research,47,p.p 3931-3946,2013.

[2]. Tyagi S, Sharma B, Singh P, Dobhal R. Water quality assessment in terms of water quality index. American Journal of Water Resources, 1,p.p. 34-38,2013.

[3]. T. Poonam, B. Tanushree and C. Sukalyan, "Water quality indices- important tools for water quality assessment: A review", International Journal of Advances in Chemistry,1,2013.

[4]. M.T.R. Alves, F.B. Teresa and J.C. Nabout, "A global scientific literature of research on water quality indices: trends, biases and future directions", ActaLimnologicaBrasiliensia, 26, p.p.245-253,2014.

[5]. SannaHokkanen,Amit Bhatnagar and Mika Sillanpaa, "A review on modification methods to cellulose-based adsorbents to improve adsorption capacity", Water Research, 91, p.p.156-173,2016.

[6]. Meng Nan Chong,Bo Jin,Christopher W.K. Chow and Chris Saint, "Recent developments in photocatalytic water treatment technology: A review", Water Research, 44, p.p 2997-3027,2010.

[7]. Jeffrey R. McCutcheon and Menachem Elimelech, "Influence of concentrative and dilutive internal concentration polarization on flux behavior in forward osmosis", Journal of Membrane Science, 284, p.p.237-247,2006.

[8]. Kah Peng Lee,Tom C. Arnot andDavideMattia, "A review of reverse osmosis membrane materials for desalination-Development to date and future potential", Journal of Membrane Science, 370, p.p. 1-22, 2011.

[9]. Jincai Su, Qian Yang, JooFuatTeo and Tai-Shung Chung, "Cellulose acetate nanofiltration hollow fiber membranes for forward osmosis processes", Journal of Membrane Science, 355, p.p. 36-44,2010.

[10]. Sui Zhang,Kai Yu Wang,Tai-Shung Chung,Hongmin Chen,Y.C. Jean and Gary Amy, "Well-constructed cellulose acetate membranes for forward osmosis: Minimized internal concentration polarization with an ultra-thin selective layer", Journal of Membrane Science, 360, p.p. 522-535, 2010.

[11]. Sui Zhang,Kai Yu Wang, Tai-Shung Chung, Y.C. Jean and Hongmin Chen, "Molecular design of the cellulose ester-based forward osmosis membranes for desalination", Chemical Engineering Science, 66, p.p.2008-2018, 2011.

[12]. Guo-dong Kang and Yi-ming Cao, "Development of antifouling reverse osmosis membranes for water treatment: A review", Water Research, 46, p.p.584-600,2012.

[13]. Akili D. Khawaji,Ibrahim K. Kutubkhanah and Jong-MihnWie, “Advances in seawater desalination technologies”,Desalination, 221, p.p 47-69,2007.

[14]. Sui Zhang,Kai Yu Wang, Tai-Shung Chung, Y.C. Jean and Hongmin Chen, "Molecular design of the cellulose ester-based forward osmosis membranes for desalination", Chemical Engineering Science, 66, p.p.2008-2018, 2011.

[15]. Julius Glater, Seung-kwan Hong and Menachem Elimelech, "The search for a chlorine-resistant reverse osmosis membrane", Desalination, 95, p.p. 325-345,1994.

[16]. B.S. Chanukya and Navin K. Rastogi, "Ultrasound assisted forward osmosis concentration of fruit juice and natural colorant", Ultrasonics Sonochemistry, 34, p.p. 426-435, 2017. 
[17]. Tomoki Takahashi, Masahiro Yasukawa and Hideto Matsuyama, "Highly condensed polyvinyl chloride latex production by forward osmosis: Performance and characteristics", Journal of membrane Science, 514, p.p.547-555, 2016.

[18]. Shazad Jamil, Sanghyun Jeong and Saravanamuthu Vigneswaran, "Application of pressure assisted forward osmosis for water purification and reuse of reverse osmosis concentrate from a water reclamation plant", Separation and Purification Technology, 171, p.p. 182-190, 2016.

[19]. Tewodros Nigatu Bitaw, Kiho Park and Dae Ryook Yang, "Optimization on a new hybrid Forward osmosis-Electrodialysis-Reverse osmosis seawater desalination process”, Desalination, 398, p.p. 265-281, 2016.

[20]. Juan C.Ortega-Bravo,Gonzalo Ruiz-Filippi,Andres Donoso-Bravo,Isaac E.Reyes-Caniupan and David Jeison,” Forward osmosis: Evaluation thin-film-composite membrane for municipal sewage concentration", Chemical Engineering Journal, 306, p.p. 531$537,2016$.

[21]. Alaa H.Hawari, Nagla Kamal and Ali Altaee, "Combined influence of temperature and flow rate of feeds on the performance of forward osmosis", Desalination,398, p.p. 98-105,2016.

[22]. Nhu-Ngoc Bui and Jeffrey R.Mccutcheon, "Nanoparticle-embedded nanofibers in highly permselective thin-film nanocomposite membranes for forward osmosis", Journal of Membrane Science,518, p.p.338-346, 2016.

[23]. M. Sarai Atab, A.J.Smallbone and A.P.Roskilly, "An operational and economic study of a reverse osmosis desalination system for potable water and land irrigation”, Desalination,397, p.p. 174-184, 2016.

[24]. J. Jagur-Grodzinski and O. Kedem, "Transport coefficients and salt rejection in unchanged hyperfiltration membranes", Desalination, 4, p.p. 327-341, 1966.

[25]. S. Shanmuganathan, M.A.H. Johir, A.Listowski, S.Vigneswaran and J.Kandasamy, "Sustainable Processes for Treatment of Waste Water Reverse Osmosis Concentrate to Achieve Zero Waste Discharge: A Detailed Study in Water Reclamation Plant", Procedia Environmental Sciences, 35, p.p. 930-937, 2016.

[26]. C.H. Ahn," "Carbon nanotube-based membranes: fabrication and application to desalination”, J. Ind. Eng. Chem., 18 ,p.p. 1551$1559,2012$.

[27]. X.Zheng et.al., "Sea water desalination in China: retrospect and prospect, Chem.Eng. J.,242, p.p. 404-413, 2014.

[28]. S.Lattemann and T.Hopner, "Environmental impact and impact assessment of Seawater desalination", Desalination, 220, p.p. 1-15, 2008.

[29]. P.-K. Park, “ Full-scale simulation of seawater reverse osmosis desalination processes for boron removal: effect of membrane fouling”, Water Res., 46, p.p.3796-3804, 2012.

[30]. Tzahi Y.Cath, Amy E.Childress and Menachem Elimelech, "Forward osmosis: Principles, applications, and recent developments", Journal of Membrane Science,281, p.p. 70-87,2006. 